\title{
China steps up its efforts in research and development to combat environmental pollution
}

Rapid economic development and population growth in China in the last two decades have left a legacy of widespread environmental pollution. Many experts believe that China is experiencing an unprecedented discharge of pollutants within a relatively short time compared with developed nations in which discharges were spread over a century or more. Furthermore, 'conventional' pollution has been exacerbated in recent years by emerging contaminants such as persistent organic pollutants (POPs) and endocrine disruptors (EDs). As China continues to be plagued by pollution discharges from urban and agricultural non-point pollution as well as industrial effluents, the country is also suffering from serious industrial incidents that have contaminated its rivers and lakes in the last few years, such as the Songhua River accident in Jilin and the Beijiang River accident in Guangdong in late 2005. Adding all these up, China is facing great challenges in improving environmental quality while maintaining rapid economic development. In a report comparing 142 countries in which environmental sustainability was evaluated, China was ranked 129th (Liu and Diamond, 2005).

Despite the tough measures taken by the governmental agencies and industries, there seems to be no clear decline in pollutant discharge to the environment. Recently, the Chinese authorities said acid rain caused by sulphur dioxide affected one-third of China's land mass last year, posing a threat to food safety. Emission from fossil fuel combustion and biomass burning significantly reduce local air quality and affect global tropospheric chemistry (Richter et al., 2005). In the latest assessment, State Environmental Protection Administration (SEPA) announced on its Web site (www.zhb.gov.cn) that nationwide emissions of sulphur dioxide from coal-fired power stations grew to 12.7 million tonnes in the first six months of 2006 (up 4.2 percent on the same period last year). The official environmental monitor also said its key measure of water pollution, COD, rose 3.7 percent.
In order to stabilize pollution levels to cope with rapid economic expansion, China has set a goal of cutting pollution emissions by 10 percent, adjusted for economic growth, over the next five years, and aims to reduce energy consumption per unit of domestic gross product (GDP) by 20 percent, and the discharges of $\mathrm{SO}_{2}$ and COD will by 10 percent by 2010 . In an attempt to remedy the situation the government has pledged a steady increase in investment in environmental programs. For example, US $\$ 125$ billion will be allocated to improve water quality over the next five years. The money will be put towards building desalinization plants and new sewage treatment works and replacing decrepit pipelines.

Advancement in science and technology for environmental protection will play a key role to ensure the maintenance or improvement of environmental quality, and will contribute to the development of a healthy society. Large numbers of environmental research programs have been implemented in the last few years, including a national key basic research program and a national high-tech development program funded by the Ministry of Science and Technology. In addition, key projects from the Natural Science Foundation of China (NSFC), the Chinese Academy of Sciences (CAS), other state departments and local governments have also been funded. The key basic research program has funded a number of projects on a regional basis, such as soil and air quality in the Yangtze and Pearl River deltas, mixed contamination and toxicological impacts in the Beijing-Tianjin-Bohai area; and also projects based on groups of contaminants such as POPs in particular environment. The high-tech development program focuses on novel technologies for control and remediation of contaminated environments, particularly water and air in urban areas. Soil contamination and remediation have received increasing attention in the last few years, and China is undergoing a nationwide soil quality survey coordinated by SEPA and the 
Ministry of Land and Resources. NSFC funds environmental research through its three divisions, namely the Division of Chemistry (environmental chemistry and toxicology), the Division of Geosciences (temporal and spatial distribution of contaminants, risk assessment) and the Division of Life Sciences (interactions between organisms and contaminants). CAS, as the leading national $\mathrm{R} \& \mathrm{D}$ center, targets its environmental research with strategic national need and cutting-edge frontiers of science. CAS funds its research institutes through the implementation of the knowledge innovation program (KIP), and these projects are often complementary to or synergistic with national projects. CAS also emphases strong links with local governments and industries to fulfil its role in supporting the sustainable development of the nation. During the third phase of KIP, more integrative approach will be adopted in developing new projects, and these projects will compliment with national and local environmental programs to ensure that knowledge, technology development and application, and policy making can be closely linked.

Results from most research projects have traditionally been published in Chinese and have therefore been largely inaccessible to the international scientific community. In the last five years or so, there has been a steady increase in international publications from China (Cyranoski, 2005), including environmental science and technology. Delivering papers to international journals is now considered an important indicator of the quality of research conducted in China in addition to the important function of sharing common knowledge and addressing similar problems on a worldwide basis.

Encouraged by the editor-in-chief, Professor W.J. Manning, we have worked together to compile a special issue of Environmental Pollution, aiming to bring together some representative papers to illustrate recent developments in environmental research in China, to present a general picture of environmental problems facing China, and to facilitate global collaboration in fundamental aspects of environmental pollution and global impacts of regional environmental pollution.

This issue comprises 17 papers covering three general areas, namely water, soil and air pollution. The topics of the papers range from fundamental contaminant processes and pathways to treatment technologies and toxicological effects as well as methodologies for sampling and analysis. We hope that this special issue will provide a snapshot of the diversity of environmental research conducted in a wide range of Chinese research organizations.

\section{References}

Cyranoski, D., 2005. China increases share of global scientific publications. Nature 431, 116.

Liu, J.G., Diamond, J., 2005. China's environment in a globalizing world. Nature 435, 1179-1186.

Richter, A., Burrows, J.P., Nuss, H., Granier, C., Niemeier, U., 2005. Increase in tropospheric nitrogen oxide over China observed from space. Nature 437, 129-132.

\section{Yong-Guan Zhu*} Zi-Jian Wang

Research Center for Eco-Environmental Sciences, Chinese Academy of Sciences, Beijing 100085, China *Corresponding author. Department of Soil Environmental Sciences, Chinese Academy of Sciences, 18 Shuangqing Road, Beijing 100085, China. E-mail address: ygzhu@mail.rcees.ac.cn (Y.-G. Zhu)

Lei Wang Administrative Center for China's Agenda 21 (ACCA21), 67 Suzhou Street, Beijing 100089, China

Peter Christie Department of Agricultural and Environmental Science, The Queen's University of Belfast, Newforge Lane, BT9 5PX, N. Ireland, UK

J. Nigel B. Bell Center for Environmental Policy, Imperial College London, SW7 2AZ, UK

9 September 2006 